\title{
Announcing the 2018 Magnetochemistry Travel Award for Post-Doctoral Fellows
}

\author{
Carlos J. Gómez García iD
}

Instituto de Ciencia Molecular, Parque Científico, Universidad de Valencia, C/José Beltrán,2, 46980 Paterna, Valencia, Spain; carlos.gomez@uv.es

Received: 23 February 2018; Accepted: 24 February 2018; Published: 25 February 2018

With the goal of promoting the development of early career investigators in the fields of molecular magnetism, the relationship between chemical structure and magnetism, and magnetic materials, Magnetochemistry welcomed applications for the 2018 Magnetochemistry Travel Award for post-doctoral fellows. We enjoyed a large number of very highly meritorious applications for our Travel Award. It was not an easy task to select the top candidate. Nevertheless, with the assistance of our editorial board members, we have identified one outstanding candidate. On behalf of the Editors of Magnetochemistry, I am pleased to announce the winner of the inaugural Magnetochemistry Travel Award for 2018.

The Magnetochemistry Travel Award has been granted to Dr. Fabrizio Ortu, a post-doctoral researcher in the group of David Mills at The University of Manchester, Manchester, UK (Figure 1). He will receive $800 \mathrm{CHF}$ to help support travel to present his research at the 43rd International Conference on Coordination Chemistry (ICCC 2018) in Sendai, Japan.

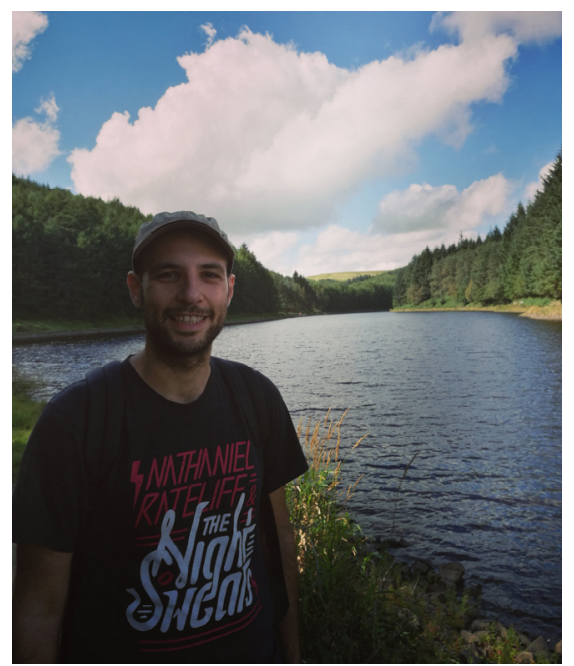

Figure 1. Dr. Fabrizio Ortu.

Dr. Fabrizio Ortu was awarded his PhD by The University of Nottingham in February 2014, where he worked under the supervision of Dr. Deborah Kays on s-block organometallic chemistry. After his PhD, he moved to the University of Manchester to work in the group of Dr. David Mills on f-element organometallic chemistry. Over the last four years, his research has been primarily aimed at studying the fundamental properties of lanthanides and actinides, such as molecular magnetism, intermolecular exchange interactions, and covalency in organometallic complexes. Since November 2016 he has been working as part of a collaborative synthetic and theoretical EPSRC-funded project for the design and synthesis of highly axial lanthanide Single Molecule Magnets (SMMs). To date, 
Dr. Ortu has co-authored 22 papers, eight of which he has written as the first author, which have been published in prestigious journals such as Nature, Nature Chemistry, and Journal of the American Chemical Society. His latest work focuses on the effect of isotopic enrichment on the relaxation of magnetization in dysprosium SMMs.

The editors, managing editor, and editorial board members congratulate Dr. Fabrizio Ortu on winning the 2018 Magnetochemistry Travel Award. We are grateful to all who submitted applications-thank you for letting us get to know you and your work. Once again, we are grateful to MDPI for their generous support of young scholars, and for helping to share their work on an international stage.

(C) 2018 by the author. Licensee MDPI, Basel, Switzerland. This article is an open access article distributed under the terms and conditions of the Creative Commons Attribution (CC BY) license (http://creativecommons.org/licenses/by/4.0/). 